\title{
DISKRIMINASI KELAS DAN GENDER DALAM NOVEL KASTA KARYA WITRI PRASETYO AJI
}

\author{
Discrimination of Class and Gender in Kasta Novels by Witri Prasetyo Aji \\ Dara Windiyarti \\ Balai Bahasa Jawa Timur \\ Jalan Siwalan Panji 2 No.1, Sidoarjo, Jawa Timur, Indonesia \\ Pos-el: darawindiyarti3@gmail.com
}

Naskah masuk: 14 Mei 2020, disetujui: 6 Juni 2020, revisi akhir: 24 Juni 2020

\begin{abstract}
Abstrak
Tujuan dari penelitian ini adalah untuk mengungkapkan diskriminasi kelas dan gender dalam novel Kasta karya Witri Prasetyo Aji yang diterbitkan pada tahun 2017 oleh Bhuana Sastra, Jakarta. Tokoh perempuan bernama Ida Ayu Made Maharani (Rani) merupakan subjek yang digunakan pengarang untuk menggugat ketidakadilan atau diskriminasi kelas dan gender yang hidup dalam masyarakat Bali. Diskriminasi kelas dan gender yang dialami tokoh Rani adalah bahwa ia harus meninggalkan kekasihnya yang berbeda kelas (kasta) dan menikah dengan laki-laki yang sederajat demi mempertahankan kadar kebangsawanannya. Namun faktanya, ia harus menderita karena ia adalah perempuan (istri) yang dianggap tidak memiliki hak yang sama dengan laki-laki (suami). Sementara, kadar kebangsawanan juga tidak menjamin kemuliaan moral seseorang. Teori yang digunakan dalam penelitian ini adalah teori feminisme. Pengumpulan data dilakukan dengan teknik kepustakaan. Metode yang digunakan dalam kajian ini adalah deskriptif analisis dengan pendekatan feminis. Berdasarkan hasil pembacaan kritis dengan pendekatan feminisme kultural diperoleh kesimpulan bahwa perempuan Bali melalui tokoh utama perempuan dalam novel tersebut berupaya melakukan resistensi terhadap dominasi patriarki yang berlaku terhadap diri mereka.
\end{abstract}

Kata kunci: perempuan, masyarakat Bali, diskriminasi kelas dan gender, feminisme

\begin{abstract}
The purpose of this study is to reveal class and gender discrimination in the Kasta novel by Witri Prasetyo Aji published in 2017 by Bhuana Sastra, Jakarta. A female figure named Ida Ayu Made Maharani (Rani) is a subject used by the author to challenge injustice or class and gender discrimination living in Balinese society. Class and gender discrimination experienced by the character Rani is that he must leave his beloved of a different class (caste) and marry a man who is equal in order to maintain his level of nobility. But the fact is, she must suffer because she is a woman (wife) who is deemed not to have the same rights as a man (husband). Meanwhile, nobility also does not guarantee one's moral dignity. The theory used in this research is the theory of feminism. Data collection is done using library techniques. The method used in this study is descriptive analysis with feminist approach. Based on the results of the critical reading using the cultural feminism approach, it was concluded that Balinese women through the main female characters in the novel sought to resist the patriarchal domination that prevailed against them.
\end{abstract}

Keywords: Women, Balinese society, class and gender discrimination, feminism

\section{PENDAHULUAN}

Menurut Hudson (1961: 10), karya sastra dipandang sebagai pengungkapan baku dari apa yang telah direnungkan dan dirasakan orang mengenai segi-segi kehidupan yang paling menarik minat secara langsung lagi kuat, pada hakekatnya adalah suatu pengungkapan kehidupan lewat bentuk bahasa. Sementara menurut Budi Darma (1987: 52), karya sastra khususnya novel, diciptakan oleh pengarang dengan tujuan 
untuk dinikmati, dipahami, dan dimanfaatkan tanpa melupakan bahwa sastra sebenarnya merupakan bagian pengungkapan masalah hidup, filsafat dan ilmu jiwa. Dengan demikian, karya sastra diyakini mengomunikasikan suatu pengalaman batin manusia berupa permasalahan kemanusiaan yang lahir dari pengarang sebagai pencipta, sekaligus sebagai bagian dari kelompok masyarakat.

Permasalahan yang diajukan oleh pengarang dapat bersifat permasalahan setempat, dapat juga bersifat kreasi rekaan yang berada dalam angan-angan pengarang. Kenyataan yang berada dalam angan-angan pengarang ini memberi kemungkinan dan keleluasaan untuk memperkenalkan pembaca pada dunia lain dengan sistem nilai kehidupan yang berbeda dengan sistem nilai kehidupan masyarakat setempat.

Berdasarkan pemikiran tersebut, novel Kasta karya Witri Prasetyo Aji yang diterbitkan oleh Bhuana Sastra pada tahun 2017 dipandang dapat digunakan sebagai sarana untuk mengungkap pemikiran tentang nilai-nilai yang hidup di tengah lingkungan budaya Bali.

Novel ini mengisahkan seorang perempuan (gadis) bangsawan Bali (Brahmana) bernama Ida Ayu Made Maharani (Rani) yang tidak bisa menikmati kehidupannya meski ia memiliki kelas sosial yang tinggi. Kenyataannya, ia justru terkungkung oleh pemikiran-pemikiran adat secara turun menurun. Sebagai seorang Brahmana, ia harus bisa menjaga dan mempertahankan derajatnya. Sehingga ketika jatuh cinta kepada seorang laki-laki yang kelas sosialnya lebih rendah yakni I Wayan Widyana (Widya), ia terpaksa meninggalkannya demi aturanaturan adat yang berlaku dalam keluarga besarnya.

Di sisi lain, ketika seorang perempuan bernama I Made Widyasari (Sari) yang berkasta Sudra menjalin kasih dengan lakilaki berkasta Brahmana bernama Ida Bagus Putu Mahendra (Hendra), juga mengalami ganjalan aturan adat. Namun, ketika adat dipaksakan untuk dilaksanakan, yakni dengan cara menikahkan Ida Ayu
Made Maharani dengan Ida Bagus Putu Mahendra, persoalan pun tidak dapat diselesaikan. Pasangan sesama bangsawan yang diharapkan dapat memberikan kebahagiaan hidup dalam rumah tangga itu justru berakhir secara tragis.

Bertolak dari beberapa peristiwa tersebut, tergambar bahwa novel Kasta mengungkapkan persoalan kelas dan gender. Struktur sosial masyarakat Bali terutama mengenai kasta menempatkan status kelompok juga individu dalam hierarki prestise masyarakat. Adanya status kelompok dan individu yang mewujud dalam perkastaan-Brahmana, Ksatria, Waisya, dan Sudra, kemudian memunculkan diskriminasi kelas. Diskriminasi itu tampak pada pembagian peran yakni pola kebutuhan, sikap, nilai, tingkah laku antarkelas (golongan) terutama antara kelas Brahmana dan kelas Sudra yang pada akhirnya menimbulkan konflik rumit yang menempatkan golongan lemah-kasta rendah pada posisi yang dikalahkan.

Gambaran pemikiran tersebut secara tidak langsung merupakan sarana mengekspresikan tradisi dan budaya Bali lewat tokoh-tokoh dan masyarakat imajiner sang pengarang. Satu dari banyak permasalahan yang diangkat dan diungkap oleh Witri Prasetyo Aji adalah diskriminasi kelas dan gender sebagaimana tergambar pada peran tokoh-tokoh dalam novel tersebut. Diskriminasi kelas yang diangkat adalah diskriminasi antara kasta Brahmana-kelas tertinggi dengan kasta Sudra-kelas terendah. Sedang diskriminasi gender yang diangkat adalah diskriminasi antara laki-laki dengan perempuan. Ketidaksetaraan kasta pada tokoh-tokoh dalam novel Kasta menimbulkan permasalahan yang berkaitan dengan konflik kelas dan konflik gender. Konflik kelas yang muncul adalah konflik antara tokoh Ida Ayu Made Maharani (Rani) dengan I Wayan Widyana (Widya); dan antara I Made Widyasari (Sari) dengan Ida Bagus Putu Mahendra (Hendra). Sedangkan konflik gender yang muncul adalah hubungan antara tokoh Ida Ayu Made Maharani (Rani) dengan tokoh 
Dara Windiyarti: Diskriminasi Kelas dan Gender dalam Novel Kasta Karya Witri Prasetyo Aji

Ida Bagus Putu Mahendra (Hendra), dan hubungan antara I Made Widyasari (Sari) dengan Ida Bagus Putu Mahendra (Hendra).

Masalah-masalah itu terasa menonjol sekaligus menjadi daya tarik dan alasan pemilihan novel Kasta sebagai objek kajian. Novel tersebut secara terbuka (berani) memaparkan aturan-aturan adat yang dipakemkan, yang kemudian memunculkan persoalan-persoalan yang menyakitkan baik pada masyakat kelas paling atas (Brahmana) maupun kelas paling bawah (Sudra), juga pada perempuan. Berdasarkan pemahaman itulah, kajian terhadap novel Kasta berjudul "Diskriminasi Kelas dan Gender dalam Novel Kasta Karya Witri Prasetyo Aji". Adapun permasalahan yang dapat dirumuskan adalah: (1) bagaimanakah diskriminasi kelas yang terjadi dalam novel Kasta?; dan (2) bagaimanakah diskriminasi gender yang terjadi dalam novel Kasta?

Pendekatan yang digunakan dalam kajian ini adalah feminis. Feminis yang berasal dari kata femme (women), berarti perempuan yang berjuang untuk memperjuangkan hak-hak kaum perempuan sebagai kelas sosial. Dalam hubungan ini, Selden (1989: 134) menyatakan, perlu dibedakan antara male dan female (sebagai aspek perbedaan biologis), masculine dan feminine (sebagai aspek perbedaan psikologis dan kultural). Male-female mengacu pada seks, sedangkan masculine-feminine mengacu pada jenis kelamin atau gender. Jadi tujuan feminis adalah keseimbangan, interelasi gender.

Budianta (2002: 201) menyatakan, feminis merupakan suatu kritik ideologis terhadap cara pandang yang mengabaikan permasalahan ketimpangan dan ketidakadilan dalam pemberian peran dan identitas sosial berdasarkan jenis kelamin. Dalam penerapannya, konsep itu diaplikasikan dengan teori Marxis, yakni memperhatikan masalah kelas dengan gender. Hal itu sejalan dengan fungsi teoriteori feminis (Ratna, 2004: 186) sebagai alat kaum wanita untuk memperjuangkan hak-haknya, erat kaitannya dengan konflik kelas dan ras, khususnya konflik gender. Artinya, antara konflik kelas dengan feminisme memiliki asumsi-asumsi yang sejajar, mendekonstruksi sistem dominasi dan hegemoni, pertentangan antara kelompok yang lemah dengan kolompok yang dianggap lebih kuat.

Feminisme menolak ketidakadilan sebagai akibat masyarakat patriarki, menolak sejarah dan filsafat sebagai disiplin yang berpusat pada laki-laki, subjek ego-centric (menggunakan pikiranpikiran), sementara wanita sebagai heterocentric (untuk orang lain). Oleh karena itulah, feminisme memiliki kaitan erat dengan Marxisme, seksisme, rasisme, dan perbudakan sebab ternyata paham-paham tersebut menyatakan adanya penindasan terhadap kelompok atau kelas lain yang lebih lemah.

Dalam hubungan itu, teori-teori feminis mencoba memberikan jalan tengah untuk menemukan keseimbangan agar kedua belah pihak memperoleh makna sesuai dengan kondisi dalam masyarakatnya. Dalam teori Marxis (Selden, 1989: 24-25), pertentangan kelas-kelas sosial mengukuhkan latar timbulnya konflikkonflik ideologis. Menurut Marx, semua sistem mental (ideologis) adalah hasil-hasil keberadaan kemasyarakatan dan keekonomian. Kepentingan keberadaan kelas masyarakat yang dominan sebagaimana orang melihat keberadaan manusia, individu dan kolektif.

Menurut Fakih (2001: 99-100), feminisme sebagai gerakan pada mulanya berangkat dari asumsi bahwa kaum perempuan pada dasarnya ditindas dan dieksploitasi, serta usaha untuk mengakhiri penindasan dan eksploitasi tersebut. Meskipun terjadi perbedaan antarfeminis dalam hal tersebut, mereka sepaham bahwa hakikat perjuangan feminis adalah demi kesamaan, martabat dan kebebasan mengontrol raga dan kehidupan baik di dalam maupun di luar rumah. Dalam hal ini, laki-laki (terutama kelas proletar) juga mengalami penderitaan yang diakibatkan oleh dominasi, eksploitasi, serta represi dari sistem yang tidak adil. 
Perlawanan terhadap ideologi gender dalam sastra melahirkan aliran feminisme yang memperjuangkan kesetaraan antara perempuan dan laki-laki (Djajanegara, 2000). Tuntutan akan kesetaraan gender itu pada umumnya hadir melalui protagonis yang biasanya digambarkan sebagai korban diskriminasi gender. Latar pun-sebagai unsur struktur yang mungkin menggambarkan suatu sistem sosial budaya yang berlaku-biasanya juga menampilkan suatu konflik gender (antara perempuan dan laki-laki). Lebih jauh dapat dikatakan bahwa penggugatan maupun pengukuhan ideologi gender dalam karya sastra akan terlihat melalui peran dan posisi tokoh-tokoh perempuan yang ada dalam karya sastra tersebut.

Mengacu paparan teori tersebut, novel Kasta dapat dikaji dengan teori feminisme. Relevansi antara novel Kasta dengan teori feminisme adalah adanya ketidakadilan atau penindasan kelompok atau kelas yang kuat terhadap kelompok (kelas) yang lebih lemah. Dalam hal ini, diskriminasi kelasperkastaan dan diskriminasi gender sangat kuat. Karena diskriminasi itu pada dasarnya "diciptakan" oleh manusia (masyarakat) berdasarkan konsesi, diskriminasi harus ditantang, dibatasi, dan diubah oleh tekanan dari luar-dalam hal ini perempuan sehingga terjadi keseimbangan antara kelas yang kuat (memiliki kekuasaan)-Brahmana dan lakilaki dengan kelas yang lemah (tidak memiliki kekuasaan)-Sudra dan perempuan. Oleh karena itu, kajian dalam tulisan ini menggunakan teori feminis untuk mengungkap hubungan antara kelas Brahmana dengan kelas Sudra, dan antara laki-laki dengan perempuan dalam segala aktivitas kehidupan bermasyarakat.

\section{METODE PENELITIAN}

Novel Kasta (2017) karya Witri Prasetyo Aji merupakan bahan yang dikaji dalam tulisan ini. Pembahasan difokuskan pada karakter tokoh-tokoh baik tokoh perempuan maupun tokoh laki-laki. Tokohtokoh tersebut memiliki status kelas yang berbeda yakni kelas atas (Brahmana)-bisa disebut kaum borjuis, dan kelas bawah (Sudra)—bisa disebut kaum proletar.

Penggolongan dalam novel ini mengacu pada status sosial tokoh-tokoh kasta Sudra yang digambarkan sebagai lemah (miskin) secara ekonomi, sementara kasta Brahmana digambarkan sebagai yang secara ekonomi kuat (kaya). Karena tujuan penelitian ini untuk mengungkap diskriminasi kelas dan gender dalam masyarakat yang memiliki hierarki, metode yang digunakan adalah metode deskriptif analitik. Menurut Ratna (2004: 53), metode deskriptif analitik dilakukan dengan cara mendeskripsikan fakta-fakta yang disusul dengan analisis. Pendekatan yang digunakan adalah pendekatan sosiologis yang akan digunakan untuk membantu memahami feminis. Pendekatan sosiologis memiliki implikasi metodologis berupa pemahaman mendasar mengenai kehidupan manusia dalam masyarakat.

Dalam penelitian ini, penulis menghubungkan cerita dan penceritaan dengan prinsip-prinsip yang ada dalam konsep teori feminisme yang diaplikasikan dengan teori Marxis yakni memperhatikan masalah konflik gender dan konflik kelas.

Dalam novel Kasta, konflik gender termanifestasi melalui tokoh perempuan sebagai kelompok lemah yang menjadi korban kekerasan laki-laki sebagai kelompok yang kuat. Sementara konflik kelas termanifestasi melalui tokoh berkasta Sudra sebagai kelompok lemah (proletar) menjadi korban marginalisasi tokoh berkasta Brahmana sebagai kelompok kuat (borjuis). Kedua persoalan itu merupakan isu yang diperbincangkan dalam feminisme dan marxisme. Dalam hubungan ini, feminisme dan marxisme dapat menemukan keseimbangan agar kedua belah pihak memperoleh makna sesuai dengan kondisi dalam masyarakatnya.

Dengan demikian, antara teks (sastra) yakni novel Kasta dengan konsep teori feminisme dan marxisme memiliki relevansi dalam mengungkapkan konflik kelas dan konflik gender melalui tokoh-tokoh yang antagonistis. Tokoh laki-laki berkonflik dengan tokoh perempuan; tokoh dari kelas sosial atas (Brahmana) berkonflik dengan 
tokoh dari kelas sosial bawah (Sudra). Keterkaitan antara peranan kelas dan gender dengan novel tersebut adalah bahwa konflik-konflik yang terjadi dalam masyarakat Kasta merupakan refleksi dari realitas diskriminasi kelas dan gender dari masyarakat Bali yang hierarkis.

\section{HASIL DAN PEMBAHASAN}

\section{Diskriminasi Kelas dalam Novel Kasta} Diskriminasi kelas dalam novel Kasta termanifestasi melalui sikap dan perilaku tokoh Ida Ayu Made Maharani (Rani) terhadap I Wayan Widyana (Widya) dan tokoh Ida Bagus Putu Mahendra (Hendra) terhadap I Made Widyasari (Sari). Ida Ayu Made Maharani (Rani), tokoh perempuan berkasta tinggi menjalin kasih dengan I Wayan Widyana (Widya), laki-laki tampan yang bekerja sebagai pelatih surfing dan pembuat tato di pantai Kuta. Meskipun Widya bukan laki-laki bangsawan, ia lakilaki tampan dan bertanggung jawab di mata Rani. Widya adalah laki-laki berkasta Sudra yang menjadi tulang punggung keluarga dengan cara bekerja sebagai pelatih surfing dan pembuat tato. Hubungan Rani dengan Widya semakin dekat meski berbeda kasta. Rani tidak ingin menempatkan dirinya sebagai orang yang memiliki derajat lebih tinggi di sisi Widya, sebagaimana terungkap pada kutipan berikut.

Bagi Rani, kasta bukan merupakan kebanggaan, melainkan penjara yang selalu membatasi pergaulannya. Terlalu dihormati dan terlalu dianggap istimewa membuat Rani merasa dirinya bagai makhluk asing. Rani hanya ingin menjadi sama seperti Sudra-Sudra lainnya, memiliki kebebasan dalam memilih jalan hidup (Aji, 2017: 44).

Kutipan tersebut secara jelas menggambarkan bahwa kasta merupakan sebuah belenggu. Orang-orang berkasta tinggi seperti Rani tidak bisa bergaul bebas dengan siapa saja. Rani sendiri menginginkan tidak terjadi perbedaan (kelas) dalam memilih jalan hidup, terutama dalam menentukan pasangan hidup. Pemikiran seperti itulah yang mengantarkan hubungan antara Rani dan Widya semakin dekat.

Kedekatan Rani dan Widya terungkap ketika Rani diajak Widya berkunjung ke Tanah Lot dan Uluwatu, tempat kenangan Widya bersama almarhum ajik (ayah) dan keluarganya. Rani sempat terharu, memeluk Widya, dan berjanji bersedia menemaninya berkunjung ke Tanah Lot dan Uluwatu setiap minggu. Widya pun berharap agar Rani tidak pernah meninggalkannya.

Di sisi lain, Rani diperkenalkan kepada Hendra oleh Awan, kakak Rani. Ketika itu Hendra berkunjung ke rumah orang tua Awan di Ubud, sementara Rani juga sedang libur kuliah dan pulang ke Ubud. Perkenalan Hendra dengan Rani membuat Hendra menyukai Rani, bahkan segera ingin melamarnya. Awan menyetujui hubungan Hendra dengan Rani. Orang tuan Rani juga sangat menyukai Hendra dan ingin menjodohkan dengan Rani. Saat Rani akan pulang ke Denpasar, ibunya meminta agar Rani mau diantar oleh Hendra. Meski Rani menolak, ibunya terus memaksanya hingga akhirnya Rani menyetujui. Rani kemudian diajak makan dulu di Kuta sebelum menuju tempat kost. Di meja makan, Rani mengungkapkan bahwa dirinya tidak menyukai perjodohan. Hendra pun menjawab bahwa perjodohan itu dilakukan untuk membahagiakan kedua orang tuanya.

\footnotetext{
"Kamu tahu kalau aku tidak menyukai perjodohan ini, kenapa kamu tetap memaksa?" Tanya Rani dengan nada sinis.

"Aku hanya ingin membahagiakan kedua orangtuaku."

Rani membelalakkan matanya. Menatap Hendra yang tetap asyik dengan makannya. "Membahagiakan kedua orangtuamu? Apa maksud kamu?"
}

"Menikah dengan perempuan Bali yang cantik, kaya, dan berkasta. Aku yakin kalau kamu cukup tahu apa maksudku" (hlm.175).

Saat Rani dan Hendra makan di sebuah restoran, tiba-tiba datang Sari dalam kondisi perut membuncit menghampiri Hendra dan memintanya untuk mempertanggungjawabkan perbuatannya. 
Hendra berpura-pura tidak mengenal Sari. Sari kemudian menyiram muka Hendra dengan minuman di depan Rani. Sari mengancam akan menghancurkan hidup Hendra seperti ia menghancurkan masa depan dirinya. Hendra sangat malu diperlakukan kasar oleh Sari di depan umum. Timbul dendam dalam diri Hendra. Ia juga merasa terancam karena Rani tidak mau menikah dengannya. Mengetahui perilaku buruk Hendra, Rani sangat marah dan mengatakan bahwa Hendra sebagai Ida Bagus tidak memiliki harga diri. Rani pun kemudian meninggalkan Hendra.

Hati Rani begitu remuk. Ia tidak tahu apa yang akan ia katakan kepada keluarganya, juga kepada Widya. Rani tidak tahu harus berbuat apa. Bagai buah simalakama, jika ia berkata jujur, Rani takut ayahnya akan kecewa dan penyakit jantungnya akan kambuh. Di lain pihak, jika Rani tetap melanjutkan perjodohan itu, bagaimana dengan Sari dan bayi yang dikandungnya. Saat hati Rani bergemuruh, datang Widya menghampirinya. Rani pun kemudian menceritakan perjodohan dirinya dengan Hendra kepada Widya. Widya terhenyak, hatinya hancur. Rani dan Widya terjebak dalam diam.

Sudah lama Rani tidak bertemu Widya. Rani kemudian mengetahui bahwa Widya masuk penjara karena telah menghajar Hendra setelah mengetahui Hendra tidak mau bertanggung jawab atas kehamilan Sari. Rani kemudian menemui Hendra di kantornya. Ia meminta Hendra mengeluarkan Widya dari penjara. Ia juga mengatakan bahwa Widya adalah kekasihnya. Hendra pun tertawa. Ia mengejek Rani yang memiliki selera rendahan, berpacaran dengan laki-laki dari kasta rendah, bahkan tak berkasta. Rani membalas, apa guna kasta kalau perilakunya bajingan. Perdebatan itu kemudian berakhir pada keputusan Hendra bersedia mengeluarkan Widya dari penjara dengan syarat Rani bersedia menikah dengannya.

Rani memang sangat prihatin atas masuknya Widya ke tahanan karena Widya adalah tulang punggung keluarganya. Dengan pertimbangan kasihan kepada keluarga Widya, juga pertimbangan atas bayi Sari yang akan digugurkan oleh Hendra, Rani bersedia menikah dengan Hendra. Rani juga berpikir bahwa cepat atau lambat ia akan tetap menikah dengan Hendra. Ia tidak mungkin mengorbankan keluarganya.

Jika diselisik lebih dalam, keputusan Rani yang bersedia menikah dengan Hendra didasari alasan membela Widya dan keluarganya sebenarnya tidak akan menyelesaikan permasalahan, justru merupakan penghancuran bagi Widya dan keluarganya. Bagaimana mungkin Rani yang telah lama menjalin kasih dengan Widya, bisa menerima Hendra, laki-laki yang telah menghamili adik kandung Widya. Keputusan itu sebenarnya lebih ke arah pertimbangan kesetaraan dan ketidaksetaraan kelas sosial. Widya yang berkasta Sudra tidak setara dengan Rani yang berkasta Brahmana, sementara Hendra yang berkasta Brahmana adalah laki-laki yang setara, sehingga dipilih sebagai suaminya demi mempertahankan kebangsawanannya. Keputusan Rani itu sungguh merupakan keputusan yang diskriminatif dan sepihak. Alasan apapun dari Rani, keputusan itu sangat menyakitkan hati Widya.

Rasa sakit hati Widya yang dahsyat muncul ketika Widya dan Saras menyaksikan dari jauh prosesi pernikahan (mepadik) Rani dan Hendra di Ubud. Widya berpikir, bagaimana mungkin, perempuan yang sangat dicintai dan telah berjanji saling mencintai justru tega meninggalkannya dengan cara menikah dengan Hendra. Kenapa harus Hendra? Dia laki-laki penghancur keluarga yang telah menghamili adiknya. Penghinaan dan penyiksaan itu terulang. Yang sebelumnya menimpa adik perempuannya, kini menimpa dirinya. Semua itu terjadi lantaran perbedaan kelas di antara Widya dan Rani. Mungkin akan berbeda jika kasta Rani sama dengan kasta Widya. Widya menerima semua itu sebagai takdir yang kejam, sebagaimana tergambar pada kutipan berikut. 
Ah, takdir. Bagi Widya, takdir sungguh begitu kejam. Perempuan yang dicintainya justru menikah lelaki yang telah menghamili adiknya. (Aji, 2017: 197).

Diskriminasi kelas itu diperkuat dengan adanya pemikiran Rani seperti kutipan berikut.

Ah, seandainya saja Bli Widya mempunyai kasta yang sama dengan keluargaku, mungkin aku berani memperjuangkan cinta kami. Namun, kenyataannya takdir memang tidak berpihak pada cintaku dan Bli Wid. Aku yakin, bila takdir sudah memihak kami, pasti ada jalan tersendiri untuk perjodohan kami (Aji, 2017: 199).

Kutipan tersebut, secara jelas menggambarkan bahwa pemikiran Rani adalah pemikiran yang bias yang memihak ke kelas atas. Ia berpendapat bahwa ia bisa memperjuangkan cintanya apabila kekasihnya (Widya) adalah laki-laki yang memiliki kasta yang dengan dirinya dan menganggap keputusannya menikah dengan Hendra, laki-laki yang sederajat sebagai takdir.

Pemikiran Rani tersebut dilatarbelakangi adanya kebiasaan dalam keluarganya tentang perjodohan antarbangsawan. Perjodohan dirinya dengan Hendra merupakan tradisi bahwa seorang Brahmana harus menikah dengan Brahmana. Semua garis keturunan dari nenek moyang Rani selalu menikah dengan kasta yang sama atu sederajat. Dengan demikian, Rani tidak berani mengubah tradisi yang akan mempermalukan keluarganya.

Diskriminasi kelas dalam novel Kasta juga dapat dilihat dari sikap dan perilaku tokoh Ida Bagus Putu Mahendra (Hendra) terhadap I Made Widyasari (Sari). Sari adalah adik perempuan Widya. Gadis cantik ini sangat berbeda dengan kakaknya. Ia adalah perempuan materialistik. Ia sudah bosan hidup miskin dan sejak kecil selalu dicaci temantemannya karena kemiskinannya. Baginya, uang dapat menentukan segalanya. Ia pun tak ragu merayu laki-laki berkewarganegaraan asing untuk mendapatkan uang.

Ketika di tempat kerjanya datang seorang eksekutif muda bernama Ida Bagus Mahendra (Hendra), anak dari bos perusahaan, Sari sangat tertarik untuk mendekati dan menggaetnya meski belum pernah bertemu.

Tanpa sengaja mereka bertemu di Kuta. Mereka pun tak tahu bahwa mereka bekerja di kantor yang sama dalam hubungan atasan-bawahan. Sari yang cantik dan seksi sementara Hendra yang tampan membuat mereka saling mengagumi pada pandangan pertama. Hubungan mereka berlanjut sampai hubungan cinta yang tanpa batas yang mengakibatkan Sari hamil. Hendra yang telah mengetahui bahwa Sari adalah anak buahnya, tak ingin karyawan di kantornya mengetahui.

Ketika Sari menuntut Hendra untuk bertanggung jawab dan menikahinya, lakilaki itu mencoba memberikan sejumlah uang untuk menggugurkan kandungannya. Sari merasa sangat terhina dengan sikap Hendra dan terus menuntut. Persoalan Hendra dengan Sari tak bisa diselesaikan dan semakin merumit.

Konflik antara laki-laki (Hendra) dengan perempuan (Sari) kemudian berkembang semakin rumit dan menimbulkan koflik kelas. Konflik kelas terjadi lantaran Sari terus menuntut Hendra untuk bertanggung jawab atas bayi dalam kadungannya. Sejenak Hendra berpikir apakah dirinya mencintai Sari, atau hanya mengagumi. Ia takut jika akan dimarahi orang tuanya. Ia lebih takut akan diusir oleh orang tuanya yang selalu menjunjung tinggi kasta dan status sosial. Pemikiran Hendra yang dilematis itu tergambar pada kutipan berikut.

Hendra di ambang dilema. Tiada hal yang bisa diperbuat selain memungkiri kenyataan. Menyakiti Sari setidaknya lebih baik daripada harus menggoreskan pilu dalam nama baik keluarga. Hendra adalah kebanggaan keluarga. Hendra harus berjodoh dengan seorang perempuan berkasta yang status sosialnya sama 
tingginya dengan keluarga Hendra (Aji, 2017: 128).

Dari kutipan tersebut tergambar adanya pemikiran yang diskriminatif dalam kelas sosial. Hendra memutuskan untuk menyakiti Sari dan mencari keselamatan diri mempertahankan status sosial dalam keluarganya. Ia memilih menggugurkan bayi yang ada dalam kandungan Sari dan meninggalkannya agar tidak tidak membuat malu keluarga yang berkasta tinggi.

Untuk menyelesaikan permasalahan dengan Sari, Hendra mengajak Sari bertemu di Kuta. Sari sangat berharap tanggung jawab Hendra, namun kenyataannya Hendra hanya menyodorkan cek kosong agar diisi oleh Sari untuk biaya menggugurkan kandungannya. Tentu saja Sari menolak keras. Sari kemudian memutuskan untuk melahirkan bayinya. Perhatikan dialog antara Hendra dengan Rani pada kutipan berikut.

"Berapa uang yang kamu mau untuk menggugurkan bayimu?" tanya Hendra tanpa basa-basi.

Hendra menyerahkan sebuah cek kepada Sari. "Kamu tulis saja berapa nominal yang kamu butuhkan,' ucap Hendra kembali.

Sari menatap lekat Hendra. Amarahnya sudah sampai pada puncaknya. Cek yang ada dalam genggamannya, disobeknya begitu saja. "Aku tidak butuh uangmu, sepeserpun aku tidak butuh. Aku hanya butuh pertanggungjawaban darimu!" ucap Sari yang mencoba untuk tenang.

Hendra tersenyum mengejek. "Pertanggungjawabanku kepadamu adalah dalam bentuk uang. Kamu harus menerimanya. Kalau kamu menginginkan aku untuk menikahimu, itu hanya mimpi. Aku sudah punya calon istri yang sederajat dengan keluargaku," ucap Hendra yang menusuk-nusuk ulu hati Sari.

Oh ya, tapi aku tidak akan pernah membiarkanmu bisa menikah dengannya!" ancam Sari dengan tegas.

"Kamu berani mengancamku?"

"Kenapa tidak? Kamu sudah menghancurkan masa depanku!"
"Menghacurkan masa depanmu? Heh, malam itu kita sama-sama menikmatinya. Dan kita melakukannya tanpa paksaan."

"Kamu ingat betul apa yang terjadi pada malam itu, lantas kenapa kamu tidak mau bertanggung jawab?"

"Karena kamu tidak sederajat!" (Aji, 2017: 184-185).

Dialog antara Hendra dan Sari pada kutipan tersebut sangat jelas merepresentasikan adanya pemikiran lakilaki bahwa status sosial dan ekonomi dapat digunakan sebagai alat untuk menyelesaikan masalah. Hendra yang memiliki kekayaan dan kasta tinggi mencoba memaksa Sari untuk menerima keputusannya bahwa dia (Sari) tidak pantas bersanding (menikah) dengan dirinya (Hendra) karena adanya perbedaan ekonomi dan kelas yang jauh. Hendra tidak berpikir bagaimana perasaan Sari dan nasib bayi dalam kandungan Sari.

Diskriminasi itu tampak pada pembagian peran yakni pola kebutuhan, sikap, nilai, tingkah laku antara laki-laki dengan perempuan, dan antara kelas Brahmana dengan kelas Sudra yang pada akhirnya menimbulkan konflik rumit yang menempatkan tokoh Sari sebagai kaum lemah yaitu perempuan berkasta rendah (Sudra) pada posisi yang dikalahkan.

Diskriminasi kelas yang terjadi dalam novel Kasta adalah diskriminasi pada lingkungan kelas Brahmana. Brahmana sebagai kelas sosial tertinggi pada masyarakat Bali, "boleh" melakukan tindakan yang merendahkan dan memarginalkan kaum lemah yaitu kasta terendah (Sudra). Tradisi mempertahankan kadar kebangsawanan dalam keluarga selalu menjadi alasannya. Alasan itulah yang digunakan Rani dan Hendra untuk meninggalkan pasangannya.

\section{Diskriminasi Gender dalam Novel Kasta}

Diskriminasi gender dalam novel Kasta mengacu pada relasi perempuan dan lakilaki. Dalam hubungan ini, perempuan selalu berada dalam posisi yang lemah atau dikalahkan, sementara laki-laki berada pada posisi kuat atau dimenangkan. 
Kedudukan perempuan berada pada posisi yang terhegemoni oleh laki-laki baik di sektor domestik maupun publik. Mereka harus bisa memahami bahwa dirinya adalah individu-individu kelas dua dalam kelompok masyarakatnya. Oleh karena itu, untuk memperoleh kebahagiaan hidup, mereka harus berjuang dengan kemampuan sendiri.

Dalam novel Kasta, diskriminasi gender termanifestasi lewat sikap dan perilaku tokoh Ida Bagus Putu Mahendra (Hendra) terhadap I Made Widyasari (Sari) dan sikap Ida Bagus Putu Mahendra (Hendra) terhadap Ida Ayu Made Maharani (Rani). Seperti telah diungkapkan di atas, tokoh I Made Widyasari (Sari) adalah perempuan materialistik yang sudah bosan hidup miskin. Ia kemudian menjalin hubungan dengan Hendra. Awal hubungan itu terjadi setelah Hendra menolong Sari ketika diganggu orang mabuk di Legian. Sari kemudian diantar pulang oleh Hendra. Mereka pun saling jatuh cinta pada pandangan pertama, seperti tergambar pada kutipan berikut.

"Sari..." Hendra kembali menyebut nama. Sepertinya, kali ini dia benar-benar jatuh hati pada gadis Bali itu.

Di Amerika, banyak gadis berkulit putih yang selalu memamerkan lekuk tubuhnya. Tapi di Bali, dia bisa melihat dengan mata kepalanya lekuk tubuh gadis yang eksotis. Gadis itu adalah Sari (Aji, 2017, hlm. 33).

"Ah, apakah aku benar-benar jatuh cinta kepadanya?" Tanya Sari kepada dirinya sendiri. Selama ini sudah puluhan lelaki yang menjadi teman kencannya. Bahkan hampir setiap malam Sari berganti pasangan. Namun tak pernah ada yang membekas seperti ini (Aji, 2017, hlm. 34).

Dari kutipan tersebut menggambarkan dua muda-mudi yang jatuh cinta secara spontan tanpa memandang status sosial dan kelas. Cinta mereka muncul karena saling mengagumi dari aspek fisik. Hendra adalah pemuda tampan yang telah menolong Sari, sementara Sari adalah gadis cantik, eksotis yang seksi.

Suatu saat pada malam minggu di Legian, Sari diketahui oleh Rani dan Widya sedang merayu bule tua. Widya langsung marah, dan menyuruh adiknya yang berpakaian seksi itu untuk pulang. Sari pun melawan kakaknya dan tidak menggubrisnya. Untuk mengurangi rasa jengkelnya setelah dimarahi kakaknya, Sari bermalam minggu sendirian di kafe Kuta. Ketika sedang meneguk minuman, datanglah Hendra. Hendra menawarkan diri untuk berjalan-jalan dengan Sari. Sari yang memang menyukai Hendra, tidak menolak. Ia dibawa ke sebuah villa di Nusa Dua. Dalam keadaan setengah mabuk, Rani dan Hendra bercinta hingga pagi. Hendra pun kemudian meninggalkan Sari sendirian dan meletakkan sejumlah uang di tempat tidur. Hedra kemudian bertemu Ida Bagus Putu Heriawan (Awan), sahabat lamanya saat SMA.

Dari peristiwa itu, dapat diketahui telah terjadi adanya penempatan peran perempuan pada posisi yang rendah dari laki-laki. Sosok Sari, yang berada di sebuah kafe untuk menikmati malam minggu, dengan mudah dibawa ke vila, kemudian diajak bercinta dalam keadaan setengah sadar oleh Hendra. Lebih parahnya, Hendra meninggalkan begitu saja di tempat tidur dengan sejumlah uang. Di sini sangat terasa bahwa perempuan sangat direndahkan, tidak dihargai, apalagi dihormati oleh laki-laki. Hal ini tentu sangat menyakitkan bagi perempuan. Sementara sosok Hendra sebagai laki-laki seolah memiliki kekuasaan penuh untuk bertindak sesuka hatinya tanpa mempertimbangkan perasaan dan penderitaan pihak perempuan.

Perilaku dua muda-mudi yang menimbulkan konflik gender tersebut secara jelas tergambar pada kutipan berikut.

Sementara Hendra sudah pergi bersama Awan, Sari baru terbangun dari nyenyaknya. Ia terkejut ketika mendapati tubuhnya telanjang seorang diri dan menemukan beberapa lembar uang ratusan ribu di sampingnya. Matanya berkeliling. Di mana Hendra? Di mana lelaki yang telah ia beri keperawanan yang selama ini ia jaga? 
Sari menarik napas panjang. Tiba-tiba ada rasa menyesal yang menyerang ulu hatinya. Kenapa semalam ia bisa menjadi perempuan bodoh? Kenapa? Kenapa Sari bisa percaya begitu saja dengan mulut Hendra dan menurut saja ketika Hendra mengajaknya tidur di resor? (Aji, 2017: 7475).

Kutipan tersebut merepresentasikan adanya ketidakadilan gender. Perilaku Hendra yang meletakkan uang di samping Sari setelah mereka bercinta menggambarkan adanya pemberian peran dan identitas sosial berdasarkan jenis kelamin. Sari sebagai perempuan cukup dibayar dengan uang setelah memberi kepuasan seksual kepada laki-laki. Hendra tak sedikit pun berpikir bahwa Sari adalah sosok yang pernah ia kagumi saat pertama bertemu. Hendra tidak pernah mempertimbangkan bahwa perempuan memiliki harga diri. Ia sangat merendahkan harga diri perempuan. Sementara Sari sebagai perempuan telah menempatkan Hendra sebagai laki-laki baik yang telah menolongnya ketika pertama bertemu. Ia begitu menyukai Hendra dan menganggapnya sebagai lakilaki baik. Ketika diajak ke villa di Nusa Dua, ia pun menurut, bahkan sampai menyerahkan harta paling berharga kepada Hendra.

Perilaku dan pemikiran tersebut yang ditolak oleh kaum feminis. Perilaku yang menempatkan perempuan sebagai makhluk yang rendah. Pemikiran-pemikiran yang menimbulkan ketidakadilan gender (perempuan) itu tidak terlepas dari akibat masyarakat patriarki. Masyarakat patriarki yang berpusat pada laki-laki, subjek egocentric (menggunakan pikiran-pikiran), sementara wanita sebagai hetero-centric (untuk orang lain).

Konflik gender antara laki-laki (Hendra) dengan perempuan (Sari) kemudian berkembang semakin rumit. Penghinaan demi penghinaan terus berlangsung di saat Sari menuntut pertanggungjawaban Hendra. Sari telah mengetahui bahwa hubungan cintanya dengan Hendra membuahkan janin dalam kandungan Sari. Dalam hal ini tentu saja Sari meminta tanggung jawab Hendra. Sari kemudian menemui Hendra ke kantor untuk membicakan persoalan kehamilannya. Hendra tidak ingin seluruh karyawan di kantornya tahu kalau dia dan Sari sudah saling kenal. Hendra kemudian mengajak Sari ke sebuah restoran di Kuta. Perhatikan dialog antara Hendra dengan Sari pada kutipan berikut.

"Kenapa pagi itu kamu pergi begitu saja? Apa maksudmu meninggalkan beberapa lembar ratusan ribu di atas meja?" tanya Sari yang tidak ingin berbasa-basi.

Hendra tersenyum sinis. "Aku sudah membelinya, jadi aku berkewajiban untuk membayarnya," jawab Hendra enteng.

"Apa maksudmu?" Tanya Sari dengan nada sedikit meninggi. Sari memang tersinggung dengan jawaban yang Hendra lontarkan. Bagi Sari, Hendra terlalu memandangnya rendah.

"Sudahlah, tidak usah berpurapura. Aku tau apa yang kamu inginkan."

Sari memandang Hendra lekatlekat. "Iya, aku memang menginginkan sesuatu darimu! Dan kamu tahu, sesuatu itu adalah pertanggungjawaban. ..... (Aji, 2017: 121).

Dari dialog antara Sari dengan Hendra pada kutipan tersebut tergambar adanya ketidakadilan gender (gender inequalities). Di sini, perempuan menjadi korban. Ketidakadilan gender tersebut termanifestasikan ke dalam bentuk pelabelan negative dan kekerasan (voilence) oleh laki-laki terhadap perempuan. Dalam hal ini, Hendra sebagai laki-laki memandang rendah (negatif) terhadap perempuan, sehingga ia berpendapat bahwa perempuan bisa dibeli. Pertanggungjawaban bisa ditukar dengan uang. Laki-laki tidak mempertimbangkan harga diri perempuan. Baginya, harga diri perempuan sama dengan uang. Sementara bagi Sari, tindakan Hendra sangat menyakitkan. Ia merasa diperlakukan sangat hina oleh Hendra, laki-laki yang pernah dikagumi sekaligus atasanya. Hatinya terus bergolak, betapa menyesal dan malu atas kehamilannya di luar nikah. 
Sari kemudian ke kantor untuk menemui Hendra lagi. Ia langsung memasuki ruang kerja Hendra dengan sangat marah dan menunjukkan selembar kertas dari dokter yang menyatakan positif hamil. Menanggapi hal itu Hendra membantah dan menganggapnya bahwa Sari adalah perempuan jalang yang hanya memanfaatkan dirinya.

\footnotetext{
"Berapa yang kamu butuhkan untuk menggugurkan bayimu?" tanya Hendra dengan penuh kesombongan.

Sari menggelengkan kepala. Tidak percaya kalau Hendra akan menuturkan kalimat serendah itu. Sari benar-benar tidak percaya (Aji, 2017: 127).
}

Kutipan tersebut, lagi-lagi menegaskan pendapat laki-laki (Hendra) bahwa perempuan sama dengan uang. Sari dianggap perempuan jalang yang biasa berkencan dengan laki-laki untuk mendapatkan uang. Bagi Hendra, berkencan dengan perempuan cukup dibayar dengan uang. Itu merupakan kebiasaan ketika ia bersekolah di Amerika. Sari mengakui kalau dirinya jalang, tetapi ia tidak pernah berhubungan seksual dengan laki-laki manapun. Bahkan ketika malam itu terjadi, ia tidak pernah berpikir untuk menyerahkan kehormatannya pada Hendra.

Dari peristiwa tersebut dapat diketahui bahwa laki-laki memiliki posisi yang lebih kuat dibanding perempuan. Laki-laki berbuat sesuka hatinya karena ia berada pada posisi yang diuntungkan yakni tidak memilki dampak langsung secara fisik dari perbuatan jahatnya. Ia juga tidak merasa malu di depan publik. Sementara perempuan berada pada posisi yang dirugikan yakni memiliki dampak langsung secara fisik dari perbuatannya yang keliru, sehingga ia harus menanggung malu di muka publik.

Diskriminasi gender lain dalam novel Kasta dapat dilihat dari sikap Ida Bagus Bagaskara (Bagas) terhadap Ida Ayu Made Maharani (Rani). Sebelum menjalin cinta dengan I Wayan Widyana (Widya), Ida Ayu Made Maharani (Rani) telah menjalin kasih dengan Ida Bagus Bagaskara (Bagas).
Setelah pindah ke Jakarta, laki-laki yang sama kasta dengan Rani itu berkhianat. Ia berselingkuh dengan beberapa gadis. Salah satunya adalah Syarah Angelina Sihotang, seorang model ternama yang cantik jelita. Atas dasar kecantikan dan ketenaran itulah Bagas menikahi Syarah.

Diskriminasi gender dalam novel Kasta yang lain termanifestasi melalui sikap dan perilaku tokoh Ida Bagus Putu Mahendra (Hendra) terhadap tokoh Ida Ayu Made Maharani (Rani). Di sini, kedua tokoh tersebut memiliki kelas sosial yang sama yaitu Brahmana, namun diskriminasi gender tidak dapat dihindari. Tokoh Hendra yang telah meninggalkan Sari dalam keadaan hamil kemudian menikahi Rani, adik dari temannya yang bernama Ida Bagus Putu Iriawan (Awan). Meski Rani telah menjalin kasih dengan I Wayan Widyana (Widya), kakak dari Sari, Rani tetap menikah dengan Hendra karena mempertimbangkan berbagai alasan. Alasan yang dipertimbangkan adalah permintaan orang tuanya agar menikah dengan orang yang memiliki kelas sederajat demi mempertahankan kadar kebangsawanan.

Setelah Hendra dan Rani menikah, mereka tinggal di Singapura. Mereka tinggal di apartemen mewah. Sebenarnya, pernikahan Rani dengan Hendra tak lebih dari keinginan sepihak saja. Rani tak lebih dari simbol kemenangan Hendra; tak lebih dari boneka sebagai pemanis setiap langkah Hendra. Rani tak pernah menemukan kehidupan yang bahagia layaknya seorang istri yang dicintai suaminya. Rani selalu diperlakukan kasar, hanya dicari ketika Hendra butuh tubuh Rani untuk memuaskannya.

Sikap Hendra terhadap Rani semakin brutal. Tak segan-segan Hendra menyiksa Rani. Rani sering mendapat tamparan dari Hendra. Meskipun Hendra bergelimang harta, tapi Hendra adalah sosok yang pelit dan jahat, bahkan cenderung seperti seorang psikopat. Rani dipaksa mengerjakan semuanya sendiri tanpa asisten rumah tangga. Rani juga tidak pernah diizinkan keluar apartemen. Dia selalu dikunci di dalam apartemen dan 
tidak diperbolehkan memiliki ponsel sendiri.

Sikap Hendra yang kejam itu tergambar pada kutipan berikut.

Rani terlelap. Entah beberapa jam dia berada dalam mimpi. Tiba-tiba ia terbangun dari tidurnya ketika seseorang menarik tangannya sedemikian kasar. Di sampingnya sudah ada Hendra yang berwajah murka. Sorot matanya seperti memancarkan sinar berwarna merah.

"Sudah puas tidurnya?" tanyanya dengan nada sinis.

Rani menggigil. Dia ketakutan. Firasatnya mengatakan, sebentar lagi dia akan mendapatkan hukuman keras.

Plak!

Benar saja tangan Hendra menampar keras Rani hingga ia terjatuh dan terantuk pinggir meja.

"Sekarang siapkan makan untukku! Cepat!" perintah Hendra dengan nada meninggi seolah Rani bukan manusia.

Hendra mulai menyendok nasi dan lauk ke dalam mulut. Tapi dia tidak langsung mengunyah. Hendra justru menyemburkan makanan itu ke wajah Rani.

"Dasar perempuan tak berguna! Makanan apa ini? Makanan anjing kausuguhkan ke suamimu?" bentak Hendra sembari menjambak rambut Rani (Aji, 2017: 297).

Dari kutipan tersebut, dapat diketahui bahwa ketidakadilan gender (gender inequalities) terjadi di semua lapisan masyarakat. Dalam hal ini, ketidakadilan gender (gender inequalities) merupakan sistem dan struktur di mana kaum perempuan menjadi korban dari sistem tersebut. Ketidakadilan gender yang dilakukan laki-laki (Hendra) terhadap perempuan (Rani) merupakan manifestasi dari marginalisasi, kekerasan (voilence), beban kerja lebih panjang dan lebih banyak (burden), dan sosialisasi ideologi nilai peran gender.

Ketidakadilan sebagai akibat masyarakat patriarki yang berpusat pada laki-laki, membuat Rani sebagai seorang isteri merasa sangat menderita atas perlakuan Hendra. Harapan untuk membahagiakan kedua orang tuanya telah mengantarkan dirinya dalam siksa yang tak berujung. Muncullah rasa dendam pada Hendra. Untuk mengakhiri penderitaannya, Rani merencanakan pembunuhan terhadap Hendra sebagaiamana tergambar pada kutipan berikut.

Rani menatap dalam lelaki yang telah menikahinya setahun yang lalu. Ada luka beserta dendam yang bersemayam. Dia ingin sekali membunuh biadap yang terbaring di sampingnya itu.

Rani bangun dari tidurnya. Dalam genggamannya, ada pisau yang sudah dipersiapkan sejak jauh hari. Untuk apalagi kalau tidak untuk ditancapkan ke perut suaminya yang laknat itu. Rani merasa, malam ini adalah malam yang pas untuk melakoni aksinya.

"Mau ke mana kamu?" tiba-tiba Mahendra terjaga. Tatapannya tajam. Kali ini Rani hanya diam dan menunduk.

"Tidur lagi! Cepat!" bentak Mahendra. Rani sama sekali tak menurutinya. Mahendra pun naik pintam, dia ingin menghajar Rani. Tapi siapa yang menyangka, Rani sudah menyiapkan benteng perlindungan. Tanpa membiarkan tubunhnya lebam kembali, ia menancapkan pisau ke perut Mahendra. Mahendra jatuh kesakitan, darah mengucur dari bekas tusukan itu (Aji, 2017: 214-215).

Usaha pembunuhan yang dilakukan Rani terhadap Hendra terjadi akibat akumulasi rasa penderitaan yang dialami Rani atas penyiksaan yang dilakukan Hendra secara terus-menerus. Rani sebagai perempuan yang memiliki kadar kebangsawanan yang sama dengan Hendra dan berstatus sebagai istri, merasa memiliki hak untuk membela diri, memberontak, dan melawan terhadap lakilaki (suami) yang terus-menerus menyiksanya. Dengan caranya sendiricenderung depresi, Rani berani menusuk perut suaminya dengan pisau.

Dari peristiwa kehidupan rumah tangga Rani dan Hendra, dapat diketahui bahwa perempuan tetap berada pada posisi lemah (dilemahkan). Hegemoni laki-laki terhadap perempuan yang terjadi di sektor domestik itu seolah merupakan kultur hegemoni, 
yakni domonasi terhadadap perempuan dari sisi persepsi dan adat.

Setelah peristiwa penusukan itu, Rani kemudian pergi meninggalkan apartemennya (Singapura). Rani kembali ke Indonesia atas bantuan Brian, teman Hendra. Sampai di Indonesia (Bali), Rani mengalami trauma berat dan depresi. Ia juga masuk tahanan atas kasus percobaan pembunuhan, setelah sembuh dari depresinya.

Keluarga Rani, terutama Awan, kakak Rani yang telah memperkenalkan dengan Hendra merasa bersalah. Mereka kemudian menyadari bahwa kasta dan materi, juga kehormatan, bukanlah jaminan akan akhlak seseorang itu mulia. Hal itu telah dibuktikan Hendra. Kehormatan keluarganya hanya merupakan benteng kebiadabannya saja. Lelaki itu benar-benar tak bermoral.

\section{SIMPULAN}

Berdasarkan analisis tersebut, dapat diambil simpulan bahwa novel Kasta merepresentasikan kehidupan masyarakat Bali yang hierarkis. Adanya kasta-kasta atau kelas-kelas, telah menciptakan diskriminasi kelas dan gender. Diskriminasi kelas yang terjadi dalam masyakat (novel) tersebut adalah adanya anggapan secara turun menurun bahwa kaum Brahmana merupakan golongan masyarakat paling tinggi. Kaum Brahmana juga harus bisa mempertahankan eksistensinya sebagai anutan bagi masyakat kelas di bawahnya seperti kaum Sudra, sehingga dalam perkawinan pun harus diatur agar kadar kebangsawanannya tidak luntur, atau bahkan hilang.

Dalam novel Kasta, masyarakat (Bali) tidak melakukan hal yang seharusnya. Untuk mempertahankan kebangwanannya, seorang pemuda berkasta brahmanya meninggalkan seorang gadis berkasta Sudra yang telah ia nodai hingga hamil. Pemuda itu meinggalkan gadis itu hanya karena ia perempuan kelas bawah yang miskin. Ia kemudian menikahi gadis yang sederajat yang sama-sama berkasta Brahmana. Namun faktanya, setelah menikahi gadis yang sederajat, ia pun menyiksa gadis yang telah menjadi istrinya itu, lantaran ia adalah laki-laki yang memilki kekuasaan untuk berbuat sesuka hatinya terhadap perempuan.

Dengan demikian, melalui novel Kasta, pengarang menyampaikan bahwa persepsi tentang perkastaan yang ada pada masyakat Bali harus benar-benar dicermati. Persepsi bahwa kaum Brahmana sebagai kasta paling tinggi selalu menjadi anutan kelas bawah (Sudra) tidak selalu benar. Baik buruknya moral manusia tidak ditentukan oleh derajat (kelas) sosial, namun dari perilaku dan tanggung jawab dalam hidup dan kehidupannya.

\section{DAFTAR PUSTAKA}

Aji, W.P. (2017). Kasta. Jakarta: Bhuana Sastra.

Budianta, M. (2002). "Pendekatan Feminisme terhadap Wacana" dalam Analisis Wacana. Yogyakarta: Penerbit Kanal.

Darma, B. (1983). Solilokui, Kumpulan Esai Sastra. Jakarta: Gramedia.

Budiman, M. (2005). "Ketika Perempuan Menulis" dalam Srintil, Edisi 8,Tahun 2005. Jakarta: Kajian Perempuan Desantra.

Eagleton, M. (Ed). (1988). Feminist Leterary Theory A Reader. New York: Basil Blackwell Inc.

Fakih, M. (2001). Analisis Gender dan Transforamasi Sosial. Yogyakarta: Pustaka Pelajar Offset.

Hudson, W.H. (1961). An Introduction to the Study of Literature. London: George G. Harrap \& Co. Ltd.

Ratna, N. K. (2004). Teori, Metode, dan Teknik Penelitian Sastra. Yogyakarta: Pustaka Pelajar.

Selden, R. (1989). A Reader's Guide to Contemporary Literary Theory. Second Edition. The University Press of Kentucky. 
Dara Windiyarti: Diskriminasi Kelas dan Gender dalam Novel Kasta Karya Witri Prasetyo Aji

Sugihastuti. (2000). Wanita di Mata Wanita. Bandung: Nuansa.

Teeuw, A. (1984). Sastra dan IImu Sastra. Bandung: PT. Dunia Pustaka Jaya.
Wellek, R. dan Austin W. (1989). Teori Kesusastraan (diterjemahkan oleh Melani Budianta). Jakarta: PT. Gramedia. 